\title{
ZNF23 Suppresses Cutaneous Melanoma Cell Malignancy via Mitochondria- Dependent Pathway
}

\author{
Xin Zhang ${ }^{a}$ Changrui Ding ${ }^{b}$ Hongfang Tianc Xinjun Dong ${ }^{d}$ Xianfu Meng ${ }^{a}$ \\ Wenwei Zhu ${ }^{a}$ Bing Liu ${ }^{a}$ Lan Wanga Min Huanga Chengxin Lia \\ aDepartment of Dermatology, Chinese People's Liberation Army General Hospital, Beijing, ${ }^{\text {bDepartment }}$ \\ of Dermatology, The First Affiliated Hospital of Qiqihar Medical College, Qiqihar, 'Department of \\ Dermatology, Hejian People's Hospital of Hebei Province, 'Department of Pathology, First Affiliated \\ Hospital and College of Basic Medical Sciences of China Medical University, Shenyang, China
}

\section{Key Words}

Cutaneous melanoma • ZNF23 • Mitochondria • Prognosis • Malignancy

\begin{abstract}
Background/Aims: Cutaneous melanoma is one of the leading causes of cancer deaths with an increasing incidence worldwide. A KRAB-containing zinc finger protein member, zinc finger 23 (ZNF23), was reduced in some types of tumors and inhibited cell growth by inducing cell cycle arrest. However, the role of ZNF23 expression is still poorly understood in melanoma. Methods: The level of ZNF23 expression was detected in cutaneous melanoma, adjacent normal skin tissues and cutaneous melanoma cell lines using immunohistochemistry and western blotting. The correlations between ZNF23 expression and other clinicopathologic parameters were analyzed in melanoma patients. Ectopic expression of ZNF23 plasmid was transfected into melanoma cells, SK-MEL-1 and SK-MEL-28. MTT, flow cytometry and transwell assay were used to measure cell proliferation, apoptosis, invasion and migration abilities, respectively. Mitochondrial functions and structures were detected by mitochondrial membrane potential assay and Transmission electron microscopy (TEM) method in melanoma cells transfected with overexpressing ZNF23 plasmid or empty vector. Western blotting was performed to detect the levels of ZNF23, p53, p27, Bcl-2 and cleaved caspase-3 after overexpressing of ZNF23 in melanoma cells. Results: ZNF23 was elevated in adjacent normal skin tissues compared with melanoma tissues. Patients with low level of ZNF23 expression exhibited higher incidence of lymphoid metastasis, thicker size of tumors and worse outcome. By using Cox's regression analysis, ZNF23 expression, tumor thickness and lymph node metastasis were the independent prognostic factors for overall survival $(p<0.05)$. Results from cellular experiments indicated that ectopic expression of ZNF23 induced cell apoptosis by activation of caspase-3, p27, p53 expression and down-regulation of $\mathrm{BCl}-2$ through mitochondria-dependent pathway. Conclusions: Decreased ZNF23 was contributed to melanoma progression and poor survival with mitochondria-dependent pathway. It indicated that ZNF23 could be a promising therapeutic biomarker candidate for cutaneous melanoma.

X. Zhang and C. Ding contributed equally to this work.

Chengxin Li, M.D, Ph.D

Department of Dermatology, Chinese PLA General Hospital, Fuxing Road, No.28,

100853, Beijing, (China)

E-Mail chengxinderm@163.com
\end{abstract}




\section{Cellular Physiology Cell Physiol Biochem 2017;43:147-157 \begin{tabular}{l|l|l} 
DOI: 10.1159/000480333 28,2017 & $\begin{array}{l}\text { O 2017 The Author(s). Published by S. Karger AG, Basel } \\
\text { www.karger.com/cpb }\end{array}$
\end{tabular}}

Zhang et al.: ZNF23 is the Promising Suppressor Gene in Melanoma

\section{Introduction}

Cutaneous melanoma has been steadily increasing worldwide with the poor 5-year survival rate. Surgery, radiotherapy and chemotherapy are considered to be the regular strategies in patients with melanoma $[1,2]$. However, it can't improve the overall survival obviously owing to the melanoma recurrence and horrible metastasis. Hence, exploring the early diagnostic biomarkers or prognostic indicators is necessary in melanoma $[3,4]$.

The human zinc finger protein 23 (ZNF23) gene is located at chr16q22.2, belonging to the Kruppel-associated box zinc-finger proteins (KRAB-ZFPs) [5]. The KRAB-finger genes encode putative regulatory proteins involved in transcriptional regulation [6]. KRABZFPs constitute the largest individual family of transcriptional repressors encoded by the higher organisms' genome, representing approximately over $1 / 3$ of about 800 different zinc finger proteins. The 75-amino acid N-terminal KRAB domain provides a site for interaction with components of the transcriptional machinery resulting in activation or repression of gene expression [7]. KRAB-ZFPs family play an important role in regulating embryonic development, cell differentiation, proliferation, apoptosis, cell cycle and malignant transformation [8]. Few evidences have been reported that ZNF23 expression was downregulated in human hepatocellular carcinoma, cervical cancer and endometrial carcinoma $[9,10]$. Moreover, ZNF23 inhibited cell proliferation and cell cycle arrest in SKOV3 and HEK293 cells after transfection of ZNF23 plasmid in melanoma cells [9].

However, the role of ZNF23 in melanoma remains unclear. Thus, we will examine the level and significance of ZNF23 expression in matched cutaneous melanoma tissues and cell lines, and we will first illustrate the hypothesis that ZNF23 functioned as a tumor suppressor gene by suppressing cell malignant behaviors via mitochondrial pathway.

\section{Materials and Methods}

\section{Melanoma cell lines and cell culture}

The cutaneous melanoma cell lines, including SK-MEL-1, SK-MEL-2, SK-MEL-5, SK-MEL-28, were purchased from American Tissue Culture Colection (ATCC) of cell line resources (https://www.atcc.org), and the human immortal keratinocyte cell line HaCat derived from the Cell Bank of BioVector NTCC Inc (http://www.biovector.net). Cells were cultured in DMEM supplemented with $10 \%$ fetal bovine serum at $37^{\circ} \mathrm{C}$ in a humidified incubator containing $5 \% \mathrm{CO}_{2}$.

\section{Melanoma specimens}

72 primary malignant cutaneous melanoma and 16 adjacent normal appearance skin tissues were collected from patients between January 2006 and December 2011 (40 men and 32 women, range from 16 to 76 years, average age 58 years). These patients did not receive any radiation or chemotherapy before operation. The survival time was calculated from the operation day to death or until the last follow-up date. All tissue sections were reviewed by two pathologists and were assessed following the 2010 WHO Classification of Tumors: Pathology and genetics of skin tumors. The use of these specimens was approved by the Ethic Committee of General PLA Hospital.

Paraffin specimens were obtained from the archives of the department of pathology. Follow-up data were obtained from review of the patients' medical records. Selected demographic information, including gender, age, tumor anatomic site, tumor thickness, Clark level, lymph node metastasis, distant metastasis, and tumor ulceration were retrieved from the hospital cancer registry. The study has been approved by the Hospitals' Ethical Review Committee.

\section{Immunohistochemistry}

Paraffin sections with a thickness of $5 \mu \mathrm{m}$ were prepared. After dewaxing in xylene and rehydrating stepwise in ethanol, antigen retrieval was carried out using $0.01 \mathrm{~mol} / \mathrm{L}$ of citrate buffer (pH 6.0) for $1 \mathrm{~min}$ $45 \mathrm{~s}$ in a pressure cooker. Immunostaining was performed by the Ultrasensitive ${ }^{\mathrm{TM}}$ streptavidin-peroxidase (S-P) Kit (MaiXin Bio, Fuzhou, China). Hydrogen peroxide (3\%) was applied to block endogenous peroxidase 


\section{Cellular Physiology Cell Physiol Biochem 2017;43:147-157 \begin{tabular}{l|l|l} 
and Biochemistry Published online: August 28, 2017 & $\begin{array}{l}\text { C) } 2017 \text { The Author(s). Published by S. Karger AG, Basel } \\
\text { www.karger.com/cpb }\end{array}$ \\
\hline
\end{tabular}}

Zhang et al.: ZNF23 is the Promising Suppressor Gene in Melanoma

activity, and normal goat serum was used to reduce nonspecific binding at $37^{\circ} \mathrm{C}$ for 30 min. Paraffin specimens were incubated with anti-ZNF23 antibody (ab68252, abcam, Cambridge, UK, dilution:1:200) at $4^{\circ} \mathrm{C}$ overnight. Biotinylated goat anti-mouse serum IgG was used as a secondary antibody. The peroxidase reaction was developed with DAB kit (Maixin Bio, Fuzhou, China), and nuclei were counterstained with hematoxylin. For negative control, the primary antibody was replaced by non-immune serum.

Two pathologists assessed the staining results on a semi-quantitative scale. Ten random views were examined per-slide, and 100 cells in each field were counted to evaluate the intensity and range of ZNF23 staining. Nuclear staining in tumor cells was considered positive staining. A negative result was given a score of 0 (no signal), faint yellow staining was recorded as a 1, yellow was scored as a 2 , and deep brown staining was recorded as a 3 . Percentage scores were assigned as 1, $\leq 25 \% ; 2,26-50 \% ; 3,51-75 \%$; and 4, $\geq 76$ $\%$. The average scores of each tumor sample were multiplied to give a final score of $0-12$, and the tumors were finally determined as negative $(-)$, score 0 ; lower expression $(+)$, score 1-4; moderate expression $(++)$, score $5-8$; and high expression $(+++)$, score $\geqq 9$. Tumor sample scored $(-)$ to $(+)$ were considered "low expression", whereas scored (++) to (+++) were considered "high expression".

\section{Ectopic expression of ZNF23 plasmid}

SK-MEL-2 and SK-MEL-28 melanoma cells were obtained from ATCC and cultured in DMEM (Hyclone, Logan, Utah, USA) containing 10\% FBS (Hyclone), $100 \mathrm{IU} / \mathrm{ml}$ penicillin (Sigma, St. Louis, MO, USA), and $100 \mathrm{mg} / \mathrm{ml}$ streptomycin (Sigma). Cells were grown on sterile tissue culture dishes and passaged every 2 days using 0.25\% trypsin (Hyclone). Ectopic expression of ZNF23 plasmid (Cat: RC203532) and empty vector (Cat: PS100001) were purchased from Origene Technologies, Inc. (Website, http://www.origene. com. Rockville, MD, USA). For transfections, SK-MEL-2 and SK-MEL-28 cells were seeded in a six-well plate $24 \mathrm{~h}$ before the experiment. The cells were transfected with overexpressing ZNF23 plasmid or empty vector mixed with Lipofectamin3000 reagent (Invitrogen, Carsland, CA, USA) according to the manufacturer's protocol. Following transfections, the protein levels were assessed at $48 \mathrm{~h}$.

\section{Western blot analysis}

Total proteins from cells and tissues were extracted in NP40 lysis buffer (Beyotime, Nanjing, China) and quantified using Bradford method. Fifty micrograms of protein was separated by 10\% SDS-PAGE and transferred to the polyvinylidene fluoride (PVDF) membranes (Millipore, Billerica, MA, USA). After blocking with 5\% BSA in Tris-buffered saline-Tween at room temperature for $2 \mathrm{~h}$, membranes were incubated with primary antibodies for ZNF23 (1:800 dilution, Proteintech, Wuhan, Hubei, China), p27 (1:1000 dilution, Cell Signal, USA), p53 (1:500 dilution, Santa Cruz, USA), Bcl-2 (1:500 dilution, Beyotime Biotech, China), activate/cleaved caspase-3 (19/17 kD, 1:500 dilution, Beyotime Biotech, China) or $\beta$-actin (1:10000, Sigma, USA) overnight at $4^{\circ} \mathrm{C}$. The membranes were incubated with peroxidase-coupled anti-mouse or rabbit IgG (Zhongshan Biotech, Beijing, China) at $37^{\circ} \mathrm{C}$ for $2 \mathrm{~h}$, and were visualized using ECL (Thermo Fisher Scientific) and detected using a BioImaging System (UVP Inc., Upland, CA, USA). The relative protein expression was calculated based on $\beta$-actin as the loading control.

\section{Cell viability assay}

Cell proliferation was determined with 3-(4, 5-dimethyl-2-thiazolyl)-2, 5-diphenyl-2-H- tetrazolium bromide (MTT) (KeyGen, Nanjing, China) according to manufacturer's instructions. Briefly, $5 \times 10^{3}$ cells were plated into 96-well plates and grew in complete medium. At different time points, cells were incubated with MTT in serum free medium at $37^{\circ} \mathrm{C}$ for $4 \mathrm{~h}$. Then the liquids were removed and $150 \mu \mathrm{l}$ DSO was added. After $10 \mathrm{~min}$ in vortex, the absorbance was measured at $490 \mathrm{~nm}$ in a microplate reader (SUNRISERC, TECAN, Switzerland). Three independent experiments were repeated.

\section{Mitochondrial Membrane Potential Detection}

Mitochondrial membrane potential was visualized in melanoma cells with 5, 5', 6, 6'-tetrachloro-1, 1', 3, 3'-tetraethylbenzimidazolcarbocyanine iodide (JC-1) following the kit's introduction.(Beyotime Co.Ltd.). Briefly describe, JC-1 is a dual-emission mitochondrial membrane potential (MMP) sensing dye, which can be accumulated and aggregates in polarized (normal) mitochondria, and aggregate JC-1 shifts its emission to red. When the mitochondrial depolarization (loss of MMP) suppress JC-1 entry into mitochondria, monomeric JC-1 remains in the cytosol and green fluorescence. Melanoma cells from different treatment 


\section{Cellular Physiology Cell Physiol Biochem 2017;43:147-157 \begin{tabular}{l|l|l} 
DOI: 10.1159/000480333 28,2017 & $\begin{array}{l}\text { O 2017 The Author(s). Published by S. Karger AG, Basel } \\
\text { www.karger.com/cpb }\end{array}$
\end{tabular}}

Zhang et al.: ZNF23 is the Promising Suppressor Gene in Melanoma

groups were washed and incubated with $\mathrm{JC}-1$ at $37^{\circ} \mathrm{C}$ for $15 \mathrm{~min}$, then washed and mounted on the confocal microscopy for imaging. The aggregate JC-1 (red) was detected at the emission wavelength of $590 \mathrm{~nm}$, and the monomeric JC-1 (green) detected at $529 \mathrm{~nm}$. The ratio of aggregates and monomeric JC-1 was used to quantify changes in MMP, and decreased JC-1 ratio represents the depolarization of mitochondria and the weakened MMP.

\section{Flow cytometry}

Cells were seeded into 6 -cm tissue culture dishes. Cells were harvested and washed with phosphatebuffered saline (PBS), then fixed in cold $70 \%$ ethanol at $4^{\circ} \mathrm{C}$ overnight. After washing twice with PBS, cells were incubated with $100 \mu \mathrm{L}$ RNase A (KeyGen, Nanjing, China) at $37^{\circ} \mathrm{C}$ for $30 \mathrm{~min}$. After staining with propidium iodide (PI, KeyGen, Nanjing, China) for $30 \mathrm{~min}$ at $4^{\circ} \mathrm{C}$, data were collected using BD FACSCalibur flow cytometer (BD Biosciences, USA). The data were analyzed using ModFit LT for Mac v3.0 (BD Biosciences, USA).

\section{Invasion and migration assay}

Transwell Migration and Matrigel-embedded Invasion Assay (Merck Millipore, Darmstadt, Germany) were used in our study following the protocol introduction. Cells were seeded at $1.5 \times 10^{5} /$ well in the upper chambers with $200 \mu \mathrm{l}$ serum-free basic medium for migration or invasion assay, then, $500 \mu \mathrm{l}$ complete endothelial cell growth medium (10\% FBS) was added in the lower wells serving as a source of chemoattractants. The cells were incubated for $24 \mathrm{~h}$ at $37^{\circ} \mathrm{C}$. Cells migrated to the lower surface of the filter were fixed with $70 \%$ methanol and stained with $0.5 \%$ crystal violet solution. The number of migrated or invasive cells was determined by counting stained cells and the average cell number per field for each well was calculated. The data was designed for three independent experiments. For each experiment, three replicate wells were used and the representative images were taken from three randomly selected fields of each well.

\section{Transmission electron microscopy (TEM)}

Transmission Electron Microscopy (TEM) observations were performed by a Hitachi 7700, AT $100 \mathrm{kV}$ (Hitachi High Technologies America Inc., Dallas, TX, USA). Melanoma Cell lines on coverslips were transfected with empty vector or ectopic expression of ZNF23 plasmid for $48 \mathrm{~h}$, and fixed in $2.5 \%$ glutaraldehyde overnight, washed with $0.1 \mathrm{M}$ phosphate-buffered saline (PBS, pH 7.2) and fixed in $2 \%$ osmium tetroxide for $2 \mathrm{~h}$. The sections were then washed twice with distilled water and stained with $1 \%$ uranyl acetate for 1 min and air-dried. The specimens were prepared for TEM observations onto 400-mesh carbon-coated copper grid and drying slowly in air naturally.

\section{Statistical analysis}

All data were analyzed with SPSS 19.0 (SPSS, Chicago, IL, USA). The measurement data were shown as the mean \pm SD. The differences between two groups were analyzed by Student's $t$-test. The impact of immunointensity of ZNF23 expression, tumor thickness and Clark level on overall survival was assessed by Kaplan-Meier analysis. The association between ZNF23 and clinicopathologic variables was analyzed using $\chi^{2}$-test method, and differences between groups were analyzed by the log-rank test. Multivariate Cox proportional hazard regression analysis was used to assess independent factors. $P$-values were based on the two sided statistical analysis, and $P$ statistical significance was assessed with a $P<0.05$.

\section{Results}

Decreased ZNF23 mostly occurred in melanoma tissues and cells

Western blot data indicated that ZNF23 was decreased in melanoma cell lines including SK-MEL-1, SK-MEL-2, SK-MEL-5, SK-MEL-28. While, high level of ZNF23 detected in the immortal keratinocyte cell line HaCat derived from adult human skin (Fig. 1A). Moreover, in seven fresh paired melanoma tissues, decrease or loss of ZNF23 was detected in melanoma tissues compared with the adjacent normal skin tissues (Fig. 1B). Furthermore, results from IHC staining exhibited that ZNF23 was specially expressed in the nuclei of cells and the high expression rate of nuclear ZNF23 were 54.2\% (39/72) in melanoma, which was significantly 


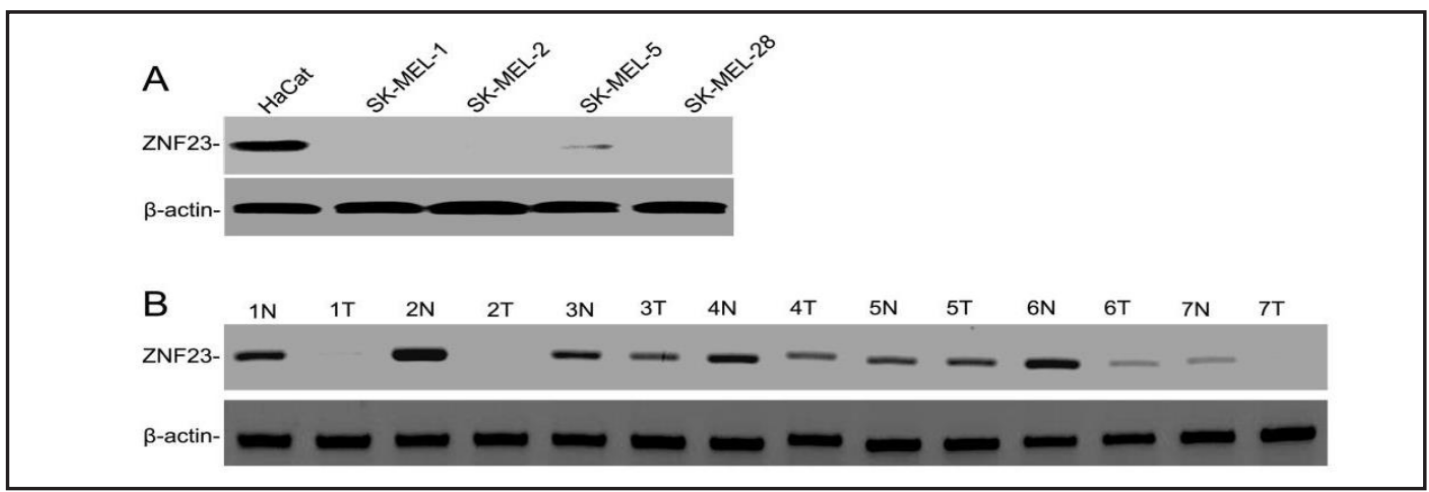

Fig. 1. Decreased ZNF23 occurred in melanoma cells and tissues by western blotting. (A) Decreased ZNF23 protein in most of melanoma compared with the immortal keratinocyte cell line HaCat derived from adult human skin; (B) The downregulation of ZNF23 protein in melanoma tissues compared with the adjacent normal skins.

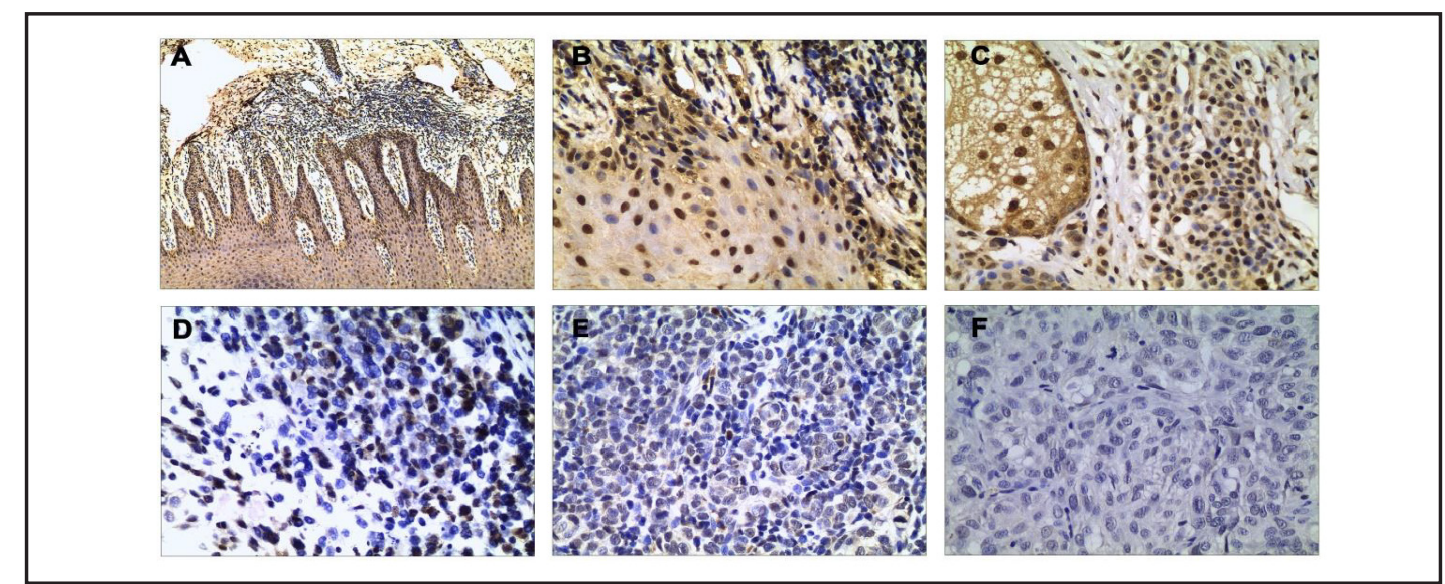

Fig. 2. Immuno-staining with anti-ZNF23 antibody on epithelium and melanoma tissues. (A) Nuclear staining for ZNF23 in normal skin epithelial cells $(\times 100)$; (B) Positive immunostaining for ZNF23 in basal epithelial cells $(\times 400)$; (C) Strong positive staining of glandular epithelium while positive expression of melanoma ( $\times 400)$; (D) Low expression of ZNF23 in melanoma $(\times 400)$; (E, F) Negative expression of ZNF23 in melanoma $(\times 400)$.

Table 1. Differential expression of ZNF23 in melanoma tissues and adjacent normal skin tissues

\begin{tabular}{lllll}
\hline Type & Total Number & \multicolumn{2}{l}{ ZNF23 expression } & $P$-value \\
& & High & Low & \\
\hline Melanoma & 72 & 39 & 33 & \\
Normal & 16 & 15 & 1 & 0.008 \\
\hline
\end{tabular}

lower than the adjacent normal skin tissues $(93.8 \%, 15 / 16)(\mathrm{P}=0.008$, Fisher's exact test, Table 1 and Fig. 2). It indicated that decreased ZNF23 occurred in most of melanoma cells and tissues.

\section{Decreased ZNF23 predicted poor prognosis in melanoma patients}

In 72 melanomas, a significant correlation between ZNF23 expression and the survival of melanoma patients was shown in Table 2 and Fig. 3C (log-rank test, $P<0.001$ ). The overallsurvival of patients with high level of ZNF23 expression (39 cases) was $62.18 \pm 2.18$ months and patients with low level of ZNF23 expression (33 cases) was $32.32 \pm 2.32$ months (Table 2 ). The overall survival was significantly lower in patients with low level of ZNF23 expression than patients with high level of ZNF23 expression.

Moreover, decreased ZNF23, age, distant metastasis, lymph node status, Clark level and tumor thickness was significantly associated with patients' survival using logistic-regressi- 


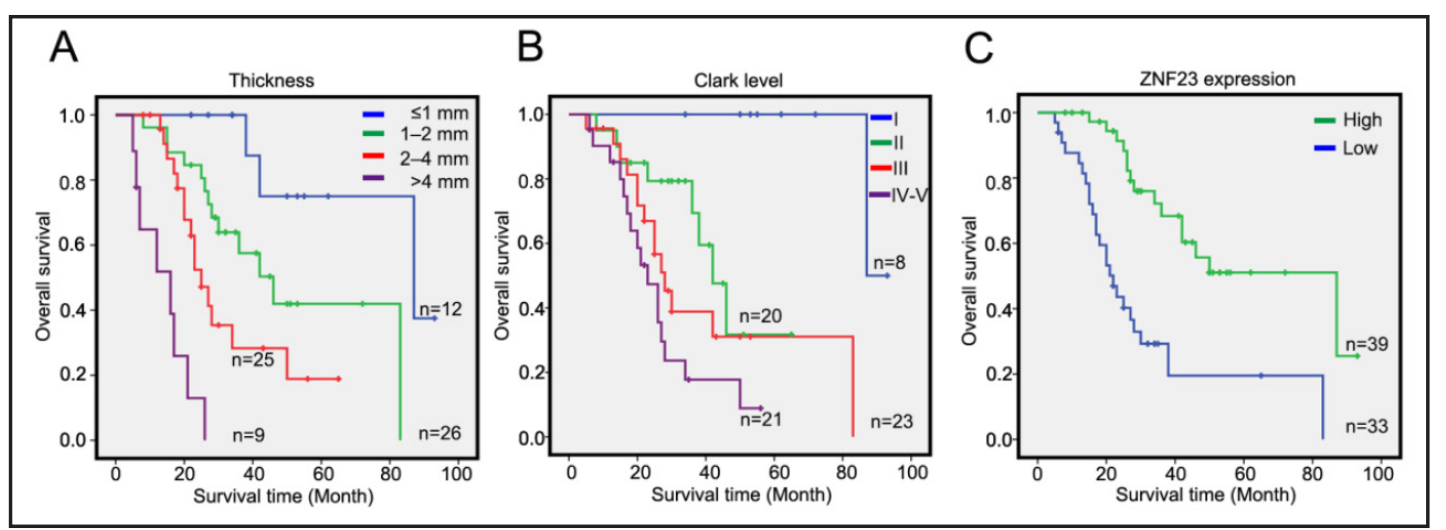

Fig. 3. Kaplan-Meier survival analyses were used in patients with cutaneous melanomas. (A )Stratified according to tumor thickness (log-rank test); (B) Stratified according to Clark level (log-rank test); (C) Stratified according to ZNF23 expression (log-rank test).

on analyses, respectively. No significant difference was observed according to tumor anatomic site, gender, and ulceration (Table 2). The influence of melanoma thickness, ulceration, and Clark level, three well-recognized prognostic factors on overall survival for cutaneous melanoma, were also assessed in this study. As shown in Fig. 3 and Table 2, both tumor thickness $(\mathrm{P}<0.05)$ and Clark level $(P<0.01)$ were also the significant prognostic factors in our patients with primary cutaneous melanoma, whereas tumor ulceration was not associated with the prognosis (Table 2 and Fig. 3).

Furthermore, the association on ZNF23 expression with other clinical features was shown in Table 3. ZNF23 expression was significantly associated with tumor thickness $(\mathrm{P}=0.015)$, lymph node status $(\mathrm{P}=0.019)$ and the final status (live or die, $\mathrm{P}=0.004$ ). ZNF23 expression rate in thick melanoma (tumor thickness $>4$
Table 2. Logistic regression analysis of clinicopathologic features in melanoma

\begin{tabular}{|c|c|c|c|c|}
\hline Clinical features & Num. & $\begin{array}{l}\text { Average survival } \\
\text { (month) }\end{array}$ & $\begin{array}{l}\text { Median survival } \\
\text { (month) }\end{array}$ & P-value \\
\hline \multicolumn{5}{|l|}{ Gender } \\
\hline Male & 40 & $45.72 \pm 5.72$ & $28.00 \pm 8.00$ & \\
\hline Female & 32 & $50.36 \pm 0.36$ & $46.00 \pm 6.00$ & 0.410 \\
\hline \multicolumn{5}{|l|}{ Age } \\
\hline$<58$ years & 35 & $38.03 \pm 8.03$ & $26.00 \pm 6.00$ & \\
\hline$\geq 58$ years & 37 & $58.05 \pm 8.05$ & $50.00 \pm 5.00$ & 0.010 \\
\hline \multicolumn{5}{|l|}{ Anatomic } \\
\hline Extremities & 15 & $54.29 \pm 4.29$ & $50.00 \pm 3.00$ & \\
\hline Trunk & 24 & $35.61 \pm 5.61$ & $34.00 \pm 4.00$ & 0.168 \\
\hline Head or neck & 33 & $53.81 \pm 3.81$ & $30.00 \pm 3.00$ & 0.983 \\
\hline \multicolumn{5}{|l|}{ Thickness } \\
\hline$\leq 1 \mathrm{~mm}$ & 12 & $77.50 \pm 7.50$ & $87.00 \pm 7.00$ & \\
\hline $1-2 \mathrm{~mm}$ & 26 & $51.88 \pm 1.88$ & $46.00 \pm 6.00$ & 0.026 \\
\hline $2-4 \mathrm{~mm}$ & 25 & $32.84 \pm 2.84$ & $25.00 \pm 5.00$ & 0.001 \\
\hline$>4 \mathrm{~mm}$ & 9 & $14.06 \pm 4.06$ & $16.00 \pm 6.00$ & $<0.001$ \\
\hline \multicolumn{5}{|l|}{ Clark level } \\
\hline I & 8 & $90.00 \pm 0.36$ & $87.00 \pm 13.02$ & \\
\hline II & 20 & $43.42 \pm 3.42$ & $42.00 \pm 2.00$ & 0.009 \\
\hline III & 23 & $42.03 \pm 2.03$ & $28.00 \pm 8.00$ & 0.002 \\
\hline IV-V & 21 & $26.05 \pm 6.05$ & $23.00 \pm 3.00$ & $<0.001$ \\
\hline \multicolumn{5}{|c|}{ Lymph node status } \\
\hline No & 37 & $66.10 \pm 6.10$ & $83.00 \pm 2.44$ & \\
\hline Yes & 35 & $26.06 \pm 6.06$ & $23.00 \pm 3.00$ & $<0.001$ \\
\hline \multicolumn{5}{|l|}{ Ulceration } \\
\hline Absent & 34 & $43.95 \pm 3.95$ & $38.00 \pm 8.00$ & \\
\hline Present & 38 & $50.86 \pm 0.86$ & $36.00 \pm 6.00$ & 0.836 \\
\hline \multicolumn{5}{|l|}{ Distant metastasis } \\
\hline No & 37 & $59.35 \pm 9.35$ & $50.00 \pm 6.00 \mathrm{t}$ & \\
\hline Yes & 35 & $28.88 \pm 8.88$ & $26.00 \pm 6.00$ & 0.001 \\
\hline \multicolumn{5}{|l|}{ ZNF23 expression } \\
\hline High & 39 & $62.18 \pm 2.18$ & $87.00 \pm 7.00$ & \\
\hline Low & 33 & $32.32 \pm 2.32$ & $22.00 \pm 2.00$ & $<0.001$ \\
\hline
\end{tabular}

mm group) was obviously lower (11.1\%) than the thickness $2-4 \mathrm{~mm}$ group (48.0\%), thickness $1-2 \mathrm{~mm}$ group (65.4\%) and thickness $<1 \mathrm{~mm}(75.0 \%)$ groups $(P=0.015$, Table 3$)$. The expression rate of ZNF23 in patients with lymph node metastasis (67.6\%) was higher than patients without lymph node metastasis $(40.0 \%, P=0.019$, Table 3$)$. These results indicated that the level of ZNF23 expression could serve as a molecular predictor for the prognosis of patients with primary cutaneous melanoma.

To investigate whether ZNF23 expression was an independent prognostic marker for cutaneous melanoma, we applied a multivariate Cox regression analysis for the overall 
survival (Table 4). The variables taken into consideration included gender, age, tumor location, thickness, Clark level, lymph node status, distant metastasis, ulceration and status of ZNF23 expression. Such analysis demonstrated that ZNF23 expression (hazard ratio $=0.306, \mathrm{P}=$ 0.002 ), tumor thickness (hazard ratio $=2.186, \mathrm{P}=0.015$ ) and lymph node status (hazard ratio $=3.310, \mathrm{P}=0.038$ ) were significant prognostic factors for cutaneous melanoma (Table 3). These data indicated that high level of ZNF23 expression was the potential independent protective factor with better outcome in melanoma patients.

Ectopic expression of ZNF23 inhibited the malignancy of melanoma cells

To determine whether ZNF23 influences proliferation and apoptosis of melanoma cells, overexpressing ZNF23 plasmid or empty vector was transfected into SK-MEL-2 and SK-MEL-28 melanoma cells. The ZNF23 expression was unaffected in cells transient transfected with empty vector, whereas ZNF23-overexpressing plasmid considerably increased the protein of level ZNF23 expression at $48 \mathrm{~h}$ after transfection using western blotting assay (Fig. 4A). Results from MTT assay revealed that overexpressing ZNF23 suppressed cell proliferation $(\mathrm{P}<0.001$, Fig. 4B) and migration or invasion ability was suppressed after ectopic expression of ZNF23 in melanoma cells, respectively (Fig. 4C and 4D). Furthermore, the apoptotic rate was elevated after overexpressing ZNF23 in melanoma accompanied by upregulation of p27, p53, cleaved caspase-3 expression and downregulation of Bcl-2 expression (Fig. 4A and 4E).
Table 3. Relationship between ZNF23 expression and other clinical characteristics in melanoma patients

\begin{tabular}{|c|c|c|c|c|}
\hline \multirow[t]{2}{*}{ Features } & \multirow{2}{*}{$\begin{array}{l}\text { Cases } \\
(\mathrm{n}=72)\end{array}$} & \multicolumn{2}{|c|}{ ZNF23 expression } & \multirow[t]{2}{*}{$P$-value } \\
\hline & & Low (\%) & High (\%) & \\
\hline \multicolumn{5}{|l|}{ Gender } \\
\hline Male & 40 & $19(47.5)$ & $21(52.5)$ & \\
\hline Female & 32 & $14(43.8)$ & $18(56.2)$ & 0.751 \\
\hline \multicolumn{5}{|l|}{ Age } \\
\hline$<58$ years & 35 & $18(51.4)$ & $17(48.6)$ & \\
\hline$\geq 58$ years & 37 & 15 (40.5) & $22(59.5)$ & 0.354 \\
\hline \multicolumn{5}{|l|}{ Anatomic } \\
\hline Extremities & 15 & $7(46.7)$ & $8(53.3)$ & \\
\hline Trunk & 24 & 15 (62.5) & $9(37.5)$ & \\
\hline Head or neck & 33 & $11(33.3)$ & $22(66.7)$ & 0.092 \\
\hline \multicolumn{5}{|l|}{ Thickness } \\
\hline$\leq 1 \mathrm{~mm}$ & 12 & $3(25.0)$ & $9(75.0)$ & \\
\hline $1-2 \mathrm{~mm}$ & 26 & $9(34.6)$ & 17 (65.4) & \\
\hline $2-4 \mathrm{~mm}$ & 25 & $13(52.0)$ & $12(48.0)$ & \\
\hline$>4 \mathrm{~mm}$ & 9 & $8(88.9)$ & 1 (11.1) & 0.015 \\
\hline \multicolumn{5}{|l|}{ Clark level } \\
\hline I & 8 & $1(12.5)$ & 7 (87.5) & \\
\hline II & 20 & $8(40.0)$ & $12(60.0)$ & \\
\hline III & 23 & $11(47.8)$ & $12(52.5)$ & \\
\hline IV-V & 21 & 13 (61.9) & 8 (38.1) & 0.112 \\
\hline \multicolumn{5}{|c|}{ Lymph node status } \\
\hline No & 37 & $12(32.4)$ & $25(67.6)$ & \\
\hline Yes & 35 & $21(60.0)$ & $14(40.0)$ & 0.019 \\
\hline \multicolumn{5}{|l|}{ Ulceration } \\
\hline Absent & 34 & $16(47.1)$ & $18(52.9)$ & \\
\hline Present & 38 & $17(44.7)$ & $21(55.3)$ & 0.844 \\
\hline \multicolumn{5}{|c|}{ Distant metastasis } \\
\hline No & 37 & $13(35.1)$ & $24(64.9)$ & \\
\hline Yes & 35 & $20(57.1)$ & $15(42.9)$ & 0.061 \\
\hline \multicolumn{5}{|l|}{ Status } \\
\hline Alive & 33 & $9(27.3)$ & $24(72.7)$ & \\
\hline Dead & 39 & $24(61.5)$ & $15(38.5)$ & 0.004 \\
\hline
\end{tabular}

Table 4. Cox regression analysis of clinicopathologic parameters and molecular signatures in melanoma

\begin{tabular}{lcc}
\hline Features & Hazard Ratio $(95 \% \mathrm{CI})$ & $P$-value \\
\hline Gender & $0.680(0.310-1.495)$ & 0.338 \\
Age & $0.746(0.327-1.701)$ & 0.486 \\
Anatomic & $1.008(0.650-1.564)$ & 0.972 \\
Thickness & $2.186(1.166-4.098)$ & 0.015 \\
Clark level & $0.974(0.512-1.852)$ & 0.936 \\
Lymph node status & $3.130(1.066-9.189)$ & 0.038 \\
Distant metastasis & $0.962(0.383-2.416)$ & 0.935 \\
Ulceration & $1.353(0.657-2.788)$ & 0.412 \\
ZNF23 expression & $0.306(0.146-0.645)$ & 0.002 \\
\hline
\end{tabular}

ZNF23 mediated the mitochondrial pathway in melanoma cells

Based on the data showing that upregulation of ZNF23 promoted cell apoptosis and decreased cell migration and invasion, we examined the some related proteins including $\mathrm{p} 27$, p53, activate caspase-3 and Bcl-2. Interestingly, most proteins were located at mitochondria. Hence, we further check the mitochondrial membrane potential variation after transfection with overexpressing ZNF23 plasmid or empty vector. As shown in Fig. 5A, decreased MMP was detected in ectopic expression of ZNF23 group apparently, and the mitochondrial cristae and microstructure were arranged in disorder after ZNF23 plasmid transfection (Fig. 5B). 

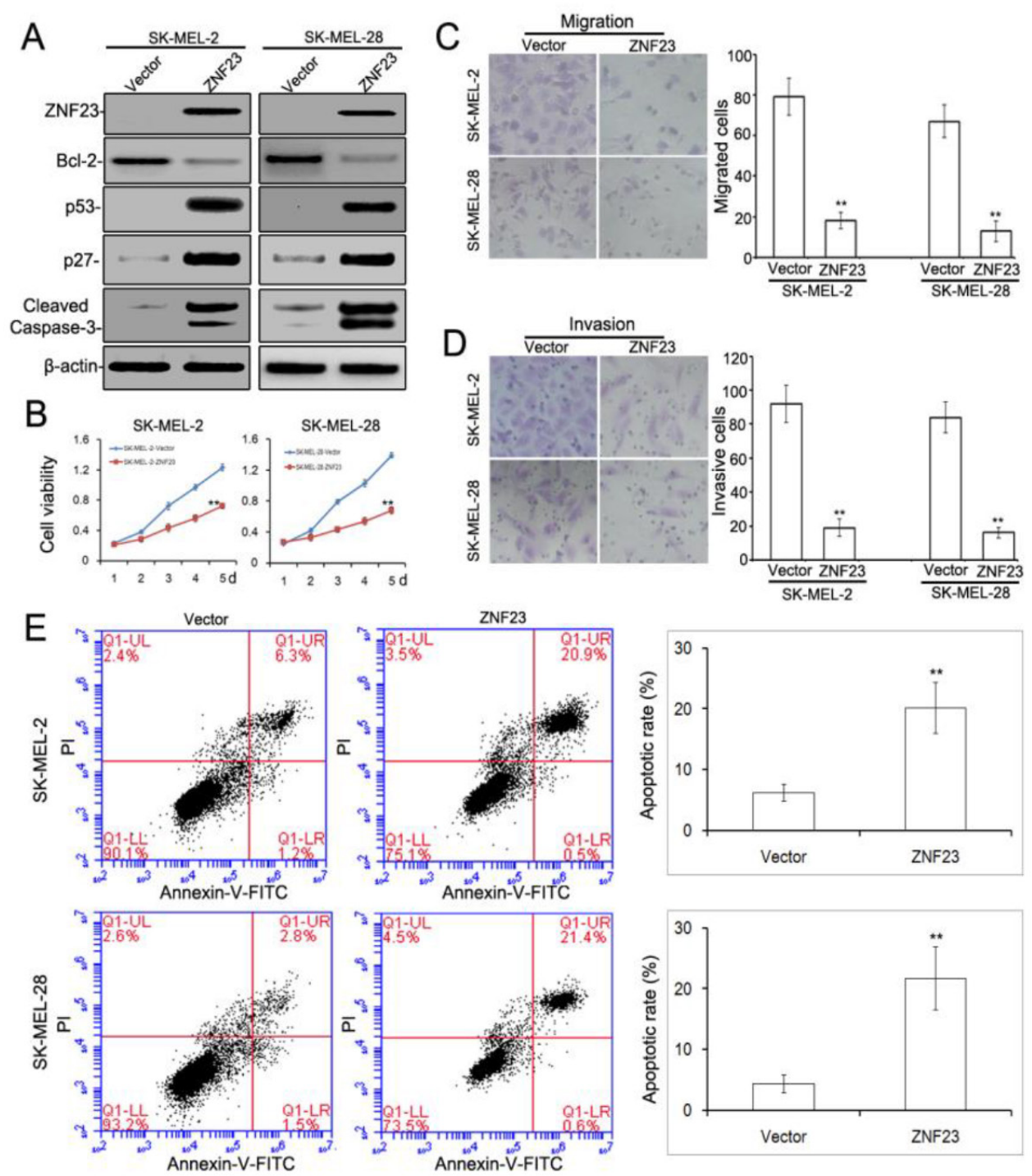

Fig. 4. Ectopic expression of ZNF23 inhibited cell proliferation, migration and invasion in melanoma cells. (A) Validation of ZNF23, Bcl-2, p27, p53 and active caspase-3 protein expression levels transfected by ZNF23 overexpressing plasmid or empty vector using western blotting analysis. (B) ZNF23 inhibited cell viability by MTT assay. (C) The transwell assay was used to determine melanoma cell migration of overexpressing ZNF23 plasmid and vector-control transfectants. Data show the mean \pm S.D. (three independent experiments); (D) The transwell assay was used to determine melanoma cell invasion of overexpressing ZNF23 plasmid and vector-control transfectants. Data show the mean \pm S.D. (three independent experiments); (E) Cell apoptosis was determined by with Annexin-V/PI staining after transfection with control and ZNF23 overexpressing plasmids. The data shown were representative of three independent experiments. ${ }^{* *} \mathrm{P}<$ 0.001 .

\section{Discussions}

Human cutaneous melanoma is an aggressive disease with the highest increase in incidence worldwide. In the past decade, tremendous advances have been made in elucidating the mechanism of melanoma initiation and progression. The treatment of melanoma has greatly improved which includes surgery for localized melanoma and regional lymph node metastases, radiation, chemotherapy, or a combination of natural chemicals, gene therapy 
Fig. 5. TEM was used to detect the mitochondrial ultramicrostructure in melanoma cells, and we found a marked difference in mitochondrial morphologies between two groups with transfection of ZNF23 overexpression plasmid or empty vector, respectively. (A) MMP was decreased in ZNF23-overexpressing melanoma cells. (B) The mitochondria were basically in a state of fusion and the mitochondrial cristae had a relatively regular arrangement in melanoma cells transfected with empty vector. However, after overexpression of ZNF23 in melanoma cells, most of the mitochondria presented short rod-like structures and spheroids, especially the mitochondrial cristae were arranged in disorder (bar = $500 \mathrm{~nm}$ ).

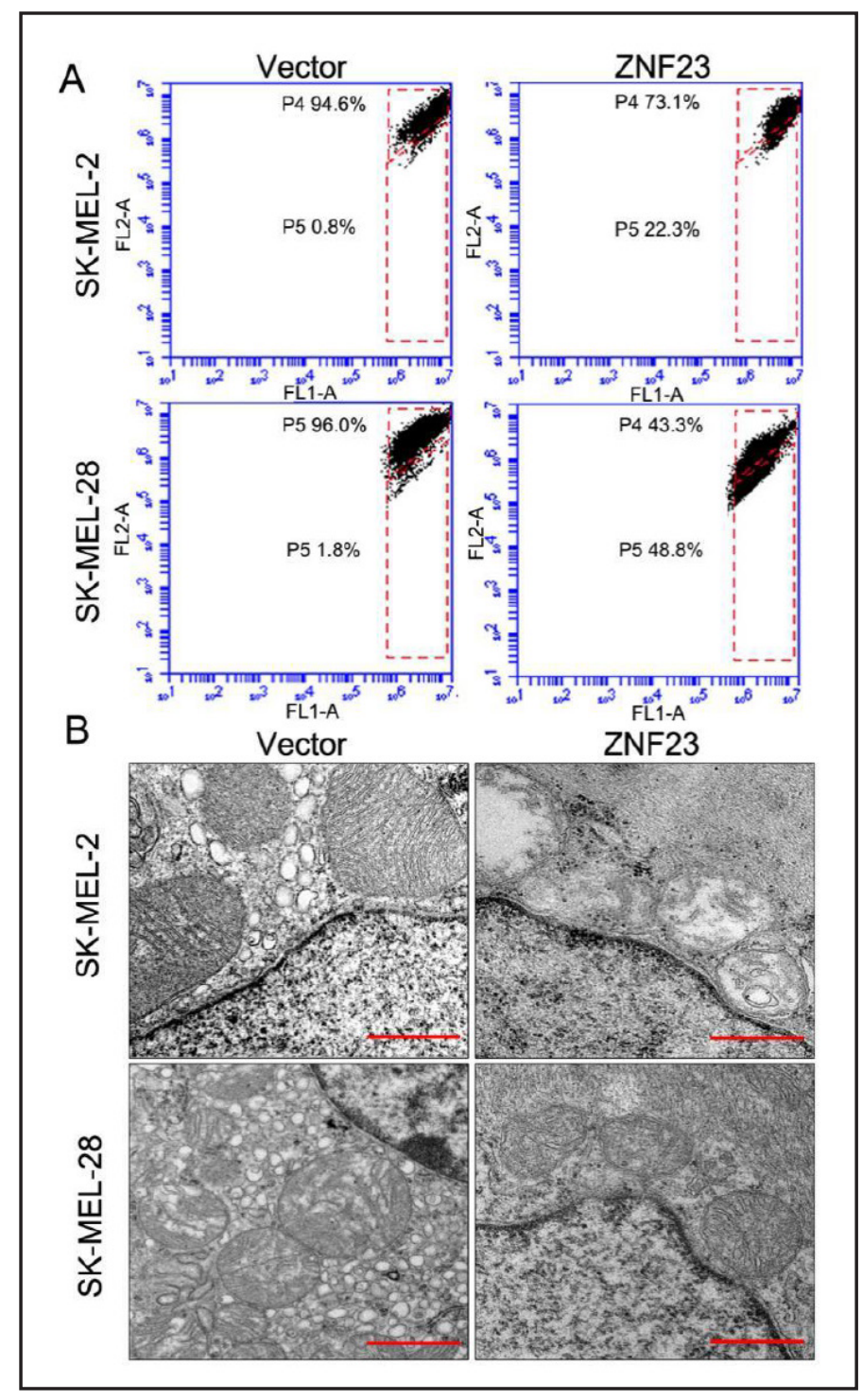

and immunotherapy to suppress melanoma metastasis in vitro and in vivo [11-13]. However, the long term prognosis of metastatic melanoma remains unsatisfactory and the underlying mechanism in melanoma pathogenesis and progression is poorly understood. Therefore, identifying useful biomarkers and exploring novel therapeutic targets remain important.

In this study, we first discovered that ZNF23 was decreased in cutaneous melanoma tissues compared with normal skin. Decreased ZNF23 expression was associated with poor progression of cutaneous melanoma. Importantly, low level of ZNF23 expression was associated with tumor thickness, lymph node metastasis. The multivariate Cox regression analysis on the overall survival revealed that ZNF23 was a significant independent prognostic factor in melanoma patients. These data further support the hypothesis that ZNF23 is a potential tumor suppress gene in melanoma, and decreased ZNF23 was involved in the malignancy of melanoma.

ZNF23 was reduced generally in human endometrial carcinoma, hepatocellular carcinoma and ovarian adenocarcinoma cell lines and tissues $[9,10]$. Our results were similar with other reports. ZNF23 was related to the cellular apoptosis in HepG2 cells with cisplatin treatment. Upregulation of p27 was detected in hepatocellular carcinoma after ectopic expression of ZNF23 plasmid with a dose-dependent manner [10]. Besides, SK-OV-3 cells with overexpressing ZNF23 induced apoptosis through elevation of p27 and activation 


\section{Cellular Physiology Cell Physiol Biochem 2017;43:147-157 \begin{tabular}{ll|l} 
DOI: 10.1159/000480333 & and Biochemistry & O2017 The Author(s). Published by S. Karger AG, Basel \\
wwww.karger.com/cpb
\end{tabular}

of caspase-3 compared with empty control [9]. In our study, upregulation of p27 and activation of caspase-3 induced by ZNF23 transfection were contributed for the inhibition of cell migration, invasion and proliferation in melanoma. The accumulating body of evidence provided the ZNF23/p53 signaling ample rationale in many types of cancer [14-16]. Loss of p27 upregulates MnSOD expression through STAT3-signaling pathway, with disruption of intracellular redox activity and enhances cell migration [17]. Cell-cycle related proteins such as p27, p16 $6^{\mathrm{INK} 4 \mathrm{a}}$ and p14 ${ }^{\mathrm{ARF}}$ were frequently decreased in melanoma tissues and overexpression of these genes suppressed the proliferation and migration of human melanoma cells through $\mathrm{Rb}$ and p53 tumor suppressor pathways [18-21] Interestingly, p53 tumor suppressor is central to the antineoplastic activity and exerts a direct pro-apoptotic role at the mitochondria by engaging in ROS-p53 interactions with anti- and pro-apoptotic Bcl-2 family members $[22,23]$. In our study, the mitochondria structure was disrupted with decreased MMP after overexpressing ZNF23 in melanoma cells, accompanied with mitochondriarelated apoptosis with downregulation of Bcl-2 expression and activation of caspase- 3 and p53. Importantly, p53, the transcription factor, directly targets mitochondria for cell death induction in the majority of human cancers [24], and it indicates that mitochondria is a potential target for tumor therapy [25-28], because mitochondria as the cells powerhouses, are essential for maintaining cell life, and they also play a major role in regulating cell death, which occurs upon permeabilization of their membranes. Once mitochondrial membrane permeabilization (MMP) occurs, cells die either by apoptosis or necrosis by mobilization and targeting to mitochondria of Bcl-2 family members.

Collectively, we first reported that ZNF23 was the potential tumor suppressor gene in melanoma patients via mitochondrial dysregulation. ZNF23 was a candidate biomarker for the assessment of tumour prognosis in melanoma. Our results indicated that ZNF23mitochondrial p53 pathway could become exploitable targets for new melanoma therapeutics.

\section{Abbreviations}

ZNF23 (Zinc finger 23); DMEM (Dulbecco's modified eagle's medium); MTT (3-(4, 5-dimethyl-2-thiazolyl)-2, 5-diphenyl-2-H-tetrazolium bromide); TEM (Transmission electron microscope); JC-1 (5, 5', 6, 6'-tetrachloro-1, 1', 3, 3'-tetrethyl benzimidalyl carbocyanine iodide); MMP (Mitochondrial membrane potential).

\section{Disclosure Statement}

The authors declare no competing financial interest.

\section{References}

$>1$ Moyer JS: The Increasing Incidence of Melanoma: It May Be More Than a Freckle. JAMA Facial Plast Surg 2017;19:62-63.

-2 Hubner J, Waldmann A, Geller AC, Weinstock MA, Eisemann N, Noftz M, Bertram S, Nolte S, Volkmer B, Greinert R, Breitbart E, Katalinic A: Interval cancers after skin cancer screening: incidence, tumour characteristics and risk factors for cutaneous melanoma. Br J Cancer 2017;116:253-259.

3 Sabel MS, Liu Y, Lubman DM: Proteomics in melanoma biomarker discovery: great potential, many obstacles. Int J Proteomics 2011;2011:181890.

4 Pardo M, Dwek RA, Zitzmann N: Proteomics in uveal melanoma research: opportunities and challenges in biomarker discovery. Expert Rev Proteomics 2007;4:273-286.

5 Cannizzaro LA, Aronson MM, Thiesen HJ: Human zinc finger gene ZNF23 (Kox16) maps to a zinc finger gene cluster on chromosome 16q22, and ZNF32 (Kox30) to chromosome region 10q23-q24. Hum Genet 1993;91:383-385. 


\section{Cellular Physiology Cell Physiol Biochem 2017;43:147-157 \begin{tabular}{l|l|l} 
and Biochemistry & DOI: 10.1159/000480333 & $\begin{array}{l}\text { (c) } 2017 \text { The Author(s). Published by S. Karger AG, Basel } \\
\text { www.karger.com/cpb }\end{array}$
\end{tabular}

6 Huang C, Jia Y, Yang S, Chen B, Sun H, Shen F, Wang Y: Characterization of ZNF23, a KRAB-containing protein that is downregulated in human cancers and inhibits cell cycle progression. Exp Cell Res 2007;313:254263.

7 Bellefroid EJ, Poncelet DA, Lecocq PJ, Revelant 0, Martial JA: The evolutionarily conserved Kruppelassociated box domain defines a subfamily of eukaryotic multifingered proteins. Proc Natl Acad Sci USA 1991;88:3608-3612.

8 Lupo A, Cesaro E, Montano G, Zurlo D, Izzo P, Costanzo P: KRAB-Zinc Finger Proteins: A Repressor Family Displaying Multiple Biological Functions. Curr Genomics 2013;14:268-278.

-9 Huang C, Yang S, Ge R, Sun H, Shen F, Wang Y: ZNF23 induces apoptosis in human ovarian cancer cells. Cancer Lett 2008;266:135-143.

10 Shi Y, Zheng L, Luo G, Wei J, Zhang J, Yu Y, Feng Y, Li M, Xu N: Expression of zinc finger 23 gene in human hepatocellular carcinoma. Anticancer Res 2011;31:3595-3599.

11 Cui L, Li Y, Lv X, Li J, Wang X, Lei Z, Li X: Expression of MicroRNA-301a and its Functional Roles in Malignant Melanoma. Cell Physiol Biochem 2016;40:230-244.

12 Zhao LM, Sun GG, Han LN, Liu LH, Ren FZ, Li L, Ma M, Shan BE: P-Hydroxycinnamaldehyde Induces B16-F1 Melanoma Cell Differentiation via the RhoA-MAPK Signaling Pathway. Cell Physiol Biochem 2016;38:22472260.

13 Carpinteiro A, Beckmann N, Seitz A, Hessler G, Wilker B, Soddemann M, Helfrich I, Edelmann B, Gulbins E, Becker KA: Role of Acid Sphingomyelinase-Induced Signaling in Melanoma Cells for Hematogenous Tumor Metastasis. Cell Physiol Biochem 2016;38:1-14.

14 See WL, Heinberg AR, Holland EC, Resh MD: p27 deficiency is associated with migration defects in PDGFexpressing gliomas in vivo. Cell Cycle 2010;9:1562-1567.

15 Zhang B, Ji LH, Liu W, Zhao G, Wu ZY: Skp2-RNAi suppresses proliferation and migration of gallbladder carcinoma cells by enhancing p27 expression. World J Gastroenterol 2013;19:4917-4924.

-16 Baldassarre G, Belletti B, Nicoloso MS, Schiappacassi M, Vecchione A, Spessotto P, Morrione A, Canzonieri V, Colombatti A: p27(Kip1)-stathmin interaction influences sarcoma cell migration and invasion. Cancer Cell 2005;7:51-63.

17 Zhang D, Wang Y, Liang Y, Zhang M, Wei J, Zheng X, Li F, Meng Y, Zhu NW, Li J, Wu XR, Huang C: Loss of p27 upregulates MnSOD in a STAT3-dependent manner, disrupts intracellular redox activity and enhances cell migration. J Cell Sci 2014;127:2920-2933.

18 Sharpless E, Chin L: The INK4a/ARF locus and melanoma. Oncogene 2003;22:3092-3098.

19 Bai M, Yu NZ, Long F, Feng C, Wang XJ: Effects of CDKN2A (p16INK4A/p14ARF) Over-Expression on Proliferation and Migration of Human Melanoma A375 Cells. Cell Physiol Biochem 2016;40:1367-1376.

20 Sanki A, Li W, Colman M, Karim RZ, Thompson JF, Scolyer RA: Reduced expression of p16 and p27 is correlated with tumour progression in cutaneous melanoma. Pathology 2007;39:551-557.

21 Zhang G, Cheng Y, Chen G, Tang Y, Ardekani G, Rotte A, Martinka M, McElwee K, Xu X, Wang Q Zhou Y: Loss of tumor suppressors KAI1 and p27 identifies a unique subgroup of primary melanoma patients with poor prognosis. Oncotarget 2015;6:23026-23035.

22 Liang L, Zhang Z: Gambogic Acid Inhibits Malignant Melanoma Cell Proliferation Through Mitochondrial p66shc/ROS-p53/Bax-Mediated Apoptosis. Cell Physiol Biochem 2016;38:1618-1630.

23 Liu B, Cheng Y, Zhang B, Bian HJ, Bao JK: Polygonatum cyrtonema lectin induces apoptosis and autophagy in human melanoma A375 cells through a mitochondria-mediated ROS-p38-p53 pathway. Cancer Lett 2009;275:54-60.

24 Moll UM, Marchenko N, Zhang XK: p53 and Nur77/TR3 - transcription factors that directly target mitochondria for cell death induction. Oncogene 2006;25:4725-4743.

25 Dong LF, Neuzil J: Mitochondria in cancer: why mitochondria are a good target for cancer therapy. Prog Mol Biol Transl Sci 2014;127:211-227.

26 Hickey JL, Ruhayel RA, Barnard PJ, Baker MV, Berners-Price SJ, Filipovska A: Mitochondria-targeted chemotherapeutics: the rational design of gold(I) N-heterocyclic carbene complexes that are selectively toxic to cancer cells and target protein selenols in preference to thiols. J Am Chem Soc 2008;130:1257012571.

27 Hail N, Jr.: Mitochondria: A novel target for the chemoprevention of cancer. Apoptosis 2005;10:687-705.

28 Armstrong JS: Mitochondria: a target for cancer therapy. Br J Pharmacol 2006;147:239-248. 